\title{
The Research on the Effectiveness of Budgetary Instruments of the Regional Socio-economic Systems Development
}

\author{
Tatiana Starikova \\ The Russian Presidential Academy of National Economy and Public Administration \\ Vladimir, Russia \\ E-mail: startv008@rambler.ru
}

\author{
Natalia Filimonova \\ Vladimir State University \\ Vladimir, Russia \\ E-mail: natal_f@mail.ru
}

\author{
Irina Zaitseva \\ Vladimir Branch of Russian University of Cooperation \\ Vladimir, Russia \\ E-mail: ilgakoja@mail.ru
}

\begin{abstract}
Budget is a significant instrument of regional development, which helps to solve social problems, align the level of different regions economic development and encourage the most meaningful life support projects of the state. However, it is possible to single out a number of problems constraining the efficiency of budgetary instruments use in Russia, among which there are the following: insufficient financing, low efficiency of budget resources, and a high degree of regional differentiation in Russia. The objective of this paper is to assess the impact of regional budget expenditures on Russian regions development indicators and to determine the effectiveness of budget expenditures in the achievement of socio-economic results of regional development. To meet the set goal, the methods of correlation and regression analysis have been used as they allow assessing the degree of budget expenditures influence on the socio-economic indicators of regional development. The information base for the study is represented by the Federal Treasury of Russia and the Federal State Statistics Service data. The results of the study suggest that regional budget is not currently an effective tool for regulating the socio-economic development of most territories. To solve the existing problems, it is necessary to develop an organizational and economic model of managing the socioeconomic regional development, which can provide the integration of the budget process and long-term planning at the regional level.
\end{abstract}

Keywords-budget process; regional development; efficiency of budgetary instruments

\section{INTRODUCTION}

The Russian Federation, being the largest state in the world and having a vast variety of economic and life conditions, identifies regionalism as the main principle of territory administration. Decentralization of regulatory, distribution, allocation, control, and other functions of state administration is shifting the responsibility for socioeconomic policy implementation from the federal level to the regional one. In this regard, it is necessary to set strictly defined conditions for the regional socio-economic development as a complex of objects (regional property complex, industrial enterprises, organizations, business structures, social facilities and others), processes (regional management system aimed at improving the investment climate, institutional environment development, processes of strategic and tactical planning, increasing the birth rate, commercialization of innovations, etc.) and relations (development of competitive potential, regional production motivation and support, development of public-private partnership, social well-being of the population), which are necessary and sufficient to achieve positive trends in the development of regional socio-economic systems. The compulsory elements and subsets that form the necessary conditions for the socio-economic development of the territory should include:

- The introduction of program-target management methods to the implementation of regional management, which due to external and internal conditions make it possible to "determine the most appropriate set of strategic goals and identify the effectiveness of target programs" [1]. Programoriented approaches and methodologies are to be used in areas that have the greatest impact on the state and development of regional socio-economic systems and can ensure sustainable growth at all the levels.

- Creation and practical use of an effective system of regional socio-economic development analysis and monitoring in shaping the information base for making reasonable and effective decisions. In their scientific works A.N. Bobryshev and M.Yu. Kazakov claim that such a monitoring system presupposes "assessing a wide range of indicators related to the development parameters of various economy sectors, 
the indicators of the population's level and quality of life" [2].

- Regional budget sustainability as a condition for financial support for the subjects of competence and authorities of the Russian Federation constituent entities and positive implementation of strategic directions. M.A. Grezina, O.A. Kolchina and I.K. Shevchenko presented a methodology "based on group division by the indicators characterizing the degree of budget sustainability, such as minimum budget expenditures, own budget revenues and budget arrears. The obtained indicators are combined into groups: absolute stability, regular stability, instability, absolute instability"[3], while the targeted development of the socio-economic system of the region is possible only in case of absolute stable regional budget or regular budget sustainability.

- Regional budget revenue growth is a necessary condition for strategic budget development and approval (also known as strategic development budget). The potential for regional economy strategic growth the can be provided by temporarily unused or underutilized production capacity and credit conditions customization for small and medium-sized enterprises [4].

- Establishing the enabling environment for business. The system of sustainable regional development is likely to prove efficient only in case of strong and demanded by entrepreneurs regional programs of business development, "which define the activities aimed at achieving the goals of state policy on development of small and medium-sized businesses (including certain categories of small and mediumsized businesses), carried out in constituent entities of the Russian Federation, indicating the volume and sources of financing and the result of the activities by the state authorities of the Russian Federation, responsible for these activities implementation. The main objective of regional programs for small business development is associated with creating conditions for small business growth and development, based on state support with the following specifying characteristics: increasing the prestige of small business; enhancing the role of small business in economic and public life; growth in small business efficiency; ensuring small business investment and business activity; increasing the contribution of small business in the socio-economic development and budget provision of territories; economic growth of the region; employment creation; providing the market with goods and services; growth in business activity of the population; establishing the system of state support for entrepreneurship; improving the welfare of the population, etc."[5].

- Innovative susceptibility of the region, which is formed through regional innovation policy aimed at: a) developing goals, objectives, directions and forms of activity of innovative enterprises and organizations;

b) choosing mechanisms to support innovative enterprises through innovations commercialization and implementation in the production and technological process.

According to Yu.S.Avramenko, while forming and improving the regional innovation policy there is a number of features of innovation processes in regional economic systems to be taken into account. They include "the forms for organizing the science and production integration process; the forms of an intermediate link organization between science and production (small innovative enterprises); innovation management in regional economic systems by state authorities; legal regulation; economic relations in the field of innovations associated with long-term and particularly high risk investment in it; direct government investment; multichannel private financing; restructuring. Thus, the level of innovation processes development is formed by the direction and pace of regional economic systems development in order to qualitatively transform and increase the main economic indicators" [6].

- The formation of lending capacity of the region and the availability of the regional credit market that help to smooth out regional socio-economic differentiation, promote cross-regional integration of credit resources and capital, and stimulate priority regional projects and industries development. T.K. Gomanova underlines that "the regional credit market is formed and developed under the influence of two components. On the one hand, as a part of the financial market, it operates according to the rules of the Russian Federation banking system, and, on the other hand, as a part of the regional economic system it should consider regional characteristics. This results in the need for a profound and comprehensive study of the operational conditions and determination of the credit market development vector" [7].

- Availability of effective tax regulation of regional development system. According to N.I. Sidorova, "the effectiveness of tax regulation depends on its compliance with the criteria of sufficiency and efficiency, which determine the two optimum permissible limits of taxation: the lower and the upper The lower limit is the level of budget needs: taxation cannot be lower than that for financing the basic state functions. The upper level is the level of taxpayers' solvency: taxation cannot exceed the allowable limit, since this violation can lead not only to a decrease in taxpayer incomes and, consequently, tax revenues, but also to their bankruptcy, and therefore termination of tax revenue. Thus, the sufficiency of taxation means the observance of the necessary taxation conditions for obtaining tax revenues. From the point of view of taxation efficiency, taxes are divided into distorting and non-distorting economic motivation of a subject" [8]. 
The scientific literature singles out a large number of factors affecting the insufficient effectiveness of budget processes in the regions of Russia: the problem of insufficient financing [9], inequality in regional revenues and expenditures [10], which causes regional budgets deficit [11], and low efficiency in using funds under the budget [12].

In order to identify the causes of negative processes in the economic and innovative development of the regions of Russia and determine the most effective instruments of regulatory impact on the socio-economic system of the region, which are able to neutralize the identified causes and minimize negative dynamics, in our opinion, it is necessary to assess the impact of regional budget expenditures on economic, social and innovative development indicators and determine the effectiveness of budget expenditures while achieving social and economic results of regional development.

\section{METHODS OF BUDGETARY INSTRUMENTS EFFICIENCY RESEARCH}

Nowadays, it is the budget of a constituent entity of the Russian Federation that is the most powerful tool for regional development. At its expense the state authorities of the constituent entity in accordance with the established competence, should provide the conditions for the development of economy, innovation, social sphere, living standards and assess to public goods. The assessment of the degree of budgetary instruments influence on the level of socio-economic development of the region, in our opinion, can be carried out using the method of pair correlation between expenditures of regional budgets and individual indicators of economic, social and innovative development of the regions of the Russian Federation.

To define the effectiveness of budgetary tools for the development of regional socio-economic systems, we adhered to the following stages of research.

At the first stage, the indicators characterizing the dynamics of revenue and expenditure of the consolidated budgets of the Russian Federation constituent entities were selected, as well as the indicators of the level of regions development. As an indicator characterizing the level of the national economy development, the nominal gross domestic product was used; to define the level of education development - the number of bachelor's, specialist's and master's programs students per 10,000 people; to identify the level of health care development - incidence rates per 1,000 people in the regions of Russia, to measure the level of innovative development of regions - the volume of innovative goods, works, services; and to assess the investment attractiveness of the regions - the volume of investment in fixed capital. The study employed the data from the Federal Treasury of Russia [13] and the Federal State Statistics Service [14] for 83 regions of Russia for the period from 2010 to 2016 .

In order to analyze the problems of the socio-economic development of the regions of Russia, it is necessary to assess the influence and the relations between the following pairs of factors, which should be represented by the following indicators:

- Budget expenditures of a constituent entity of the Russian Federation under the item "National economy" and the nominal of the gross regional product. This pair of indicators will allow to assess how much the budget expenditures of the region under this section affect the gross regional product and to what extent the dynamics of this indicator is related to budget expenditures for economic programs funded from the regional budget;

- Budget expenditures of a constituent entity of the Russian Federation under the item "Healthcare" and the indicator of statistical incidence cases per 1,000 people of the population (registered diseases and the disease first found in humans). This pair of indicators allows to measure the budget expenditures effectiveness in the healthcare sector and the degree of the impact of social expenditures of regional budgets on health indicators;

- Budget expenditures of a constituent entity of the Russian Federation in the "Education" item and the indicator of the number of bachelor's, specialist's and master's programs students per 10,000 people. Defining the relationship within this pair of indicators makes it possible to estimate how the expenditures on education affect the number of students enrolled in university education programs in all forms of education and how closely these indicators are related with each other;

- Budget expenditures of a constituent entity of the Russian Federation and the indicator of the volume of innovative goods, works and services. The interrelation of these indicators allows to evaluate the effectiveness of budgetary expenditures in terms of creating conditions for regional organizations and enterprises innovative development and the development of the innovation-oriented economic environment;

- Budget expenditures of a constituent entity of the Russian Federation, the indicator of the volume of innovative goods, works, services and the indicator of the volume of investments in fixed capital. The close relationship between these indicators also shows the effectiveness of regional budget expenditures in creating a favorable investment climate in the region.

The choice of the type of function was made at the second stage. In our opinion, in order to assess the impact of budget expenditures on the socio-economic indicators of regional development the linear pair correlation function should be used.

$$
r=\frac{\sum_{\mathrm{i}=1}^{\mathrm{n}}\left(\mathrm{x}_{\mathrm{i}-\overline{\mathrm{X}}}\right) *\left(\mathrm{y}_{\mathrm{i}-\overline{\mathrm{Y}}}\right)}{\sqrt{\sum_{\mathrm{i}=1}^{\mathrm{n}}\left(\mathrm{x}_{\mathrm{i}-\overline{\mathrm{X}}}\right)^{2} * \sum_{\mathrm{i}-1}^{\mathrm{n}}\left(\mathrm{y}_{\mathrm{i}-\overline{\mathrm{Y}}}\right)^{2}}}
$$


At the final stage, the conclusions were made on the effectiveness of using budgetary instruments for regional socio-economic development and the main directions for increasing their efficiency were identified.

\section{THE RESULTS OF THE RESEARCH ON BUDGETARY INSTRUMENTS USE EFFICIENCY}

The results of the correlation analysis between the abovementioned pairs of indicators allow us to draw the following conclusions:

- The share of the constituent entities of the Russian Federation, which revealed a strong correlation between the regional budget expenditures in the "National Economy" section and the gross regional product in the total number of constituent entities of the Russian Federation is $31.3 \%$ (26 out of 83 regions); $22.8 \%$ of the entities have a negative correlation for this pair of indicators (19 out of 83 regions).

- The share of the entities of the Russian Federation having a strong correlation between the regional budget expenditures for education and the number of bachelor's, specialist's and master's programs students per 10,000 people in the total number of regions is $1.2 \%$ ( 1 out of 83 subjects); $96.3 \%$ of entities have a negative correlation between these indicators (80 regions out of 83 ).
- The share of the entities of the Russian Federation having a strong correlation between the regional budget expenditures on health care and the incidence rates per 1000 people in the total number of regions is $15.6 \%$ (13 out of 83 regions); $44.5 \%$ of regions have a negative correlation for this pair of indicators (37 out of 83 regions).

- The share of entities that have a strong correlation between the total regional budget expenditures and the volume of innovative goods, works and services in the total number of entities of the Russian Federation is $34.9 \%$ (29 regions out of 83 ); $28.9 \%$ of regions have a negative correlation for this pair of indicators ( 24 out of 83 regions).

- The share of entities that have a strong correlation between total expenditures of the regional budget and the volume of investments in fixed capital in the total number of entities is $59.03 \%$ (49 regions out of 83 ); $14.4 \%$ of regions have a negative correlation for this pair of indicators (12 out of 83 regions).

The achieved results prove that regional budget is not currently viewed as an effective tool of regulating the socioeconomic development of most territories. Meanwhile, the analysis of the consolidated budgets of the constituent entities of the Russian Federation shows the steady tendency for growth and increase of the volume of budget funds, which is presented in "Table I".

TABLE I. DyNAMics OF REVENUES AND EXPENSES OF THE CONSTITUENT ENTITIES OF THE RUSSIAN FEDERATION CONSOLIDATED BUDGETS FOR 20102016, RUB BN

\begin{tabular}{|c|c|c|c|c|}
\hline \multirow[t]{2}{*}{ Period } & \multirow[t]{2}{*}{ Total revenue } & \multicolumn{3}{|c|}{ Therefrom: } \\
\hline & & Profit tax & Personal income tax & Property tax \\
\hline 2010 & 6537,3 & 1519,5 & 1790,5 & 628,2 \\
\hline 2011 & 7644,2 & 1927,9 & 1995,8 & 678,0 \\
\hline 2012 & 8064,5 & 1979,9 & 2261,5 & 785,5 \\
\hline 2013 & 8165,1 & 1719,7 & 2499,1 & 900,7 \\
\hline 2014 & 8905,7 & 1964,0 & 2693,5 & 957,5 \\
\hline 2015 & 9308,2 & 2107,6 & 2807,8 & 1068,6 \\
\hline 2016 & 9923,8 & 2279,3 & 3018,5 & 1117,1 \\
\hline $\begin{array}{l}\text { Growth rate } \\
2016 / 2010, \%\end{array}$ & 151,8 & 150,0 & 176,9 & 177,8 \\
\hline \multirow[t]{2}{*}{ Period } & \multirow{2}{*}{$\begin{array}{c}\text { Total } \\
\text { expenditures }\end{array}$} & \multicolumn{3}{|c|}{ Therefrom: } \\
\hline & & National issues & National economy & Socio-cultural activities \\
\hline 2010 & 6636,9 & 481,5 & 1103,6 & 3642,8 \\
\hline 2011 & 7679,1 & 468,8 & 1316,4 & 4526,9 \\
\hline 2012 & 8343,2 & 508,2 & 1608,5 & 5130,7 \\
\hline 2013 & 8806,6 & 546,0 & 1730,4 & 5396,6 \\
\hline 2014 & 9353,3 & 585,0 & 1779,3 & 5818,0 \\
\hline 2015 & 9479,8 & 603,2 & 1866,0 & 5872,7 \\
\hline 2016 & 9936,4 & 625,0 & 2002,5 & 607,9 \\
\hline $\begin{array}{l}\text { Growth rate } \\
2016 / 2010, \%\end{array}$ & 149,7 & 129,8 & 181,4 & 166,8 \\
\hline
\end{tabular}

According to the provided data on the status of consolidated budgets of the constituent entities of the Russian Federation, the income growth rate in 2016 compared to 2010 was $151.8 \%$, while the growth rate of revenue from personal income tax for the same period was $176.9 \%$. The growth rate of the consolidated budgets expenditures amounted to $149.7 \%$ over the same period, while the growth rate of expenditures under section 04 National economy exceeded all other sections and constituted $181.4 \%$. This statistical analysis proves our view that the state of the regional socio-economic system largely depends on a number of factors related to the geographical position of the region, its natural and climate conditions, the features of the sectoral and territorial structure of the regional 
economy, the demographic situation and others, which are extremely difficult to influence by the tools of budgetary regulation.

The study of regional socio-economic systems allows us to conclude that over the past ten years, at the federal level there has been a significant number of regulations and laws adopted and implemented, which aim at increasing the efficiency of budget expenditures, developing intergovernmental relations, introducing budgeting principles into budget management practice, transition to medium-term budget planning and development of program budgets, whose ultimate goal is to strengthen the impact of budgetary instruments and mechanisms as key elements of the system of socio-economic development of the region. However, the expected impact is not achieved and the current state of regional socio-economic systems requires developing and implementing new tools and mechanisms for budgetary regulation of both the current socio-economic status and achieving the long-term territory development goals. In our opinion, in the regional budgets structure of expenditures it is important to identify expenditure items that have the strongest potential influence on the long-term socioeconomic development of the entity in "Table II".

TABLE II. DISTRIBUTION OF EXPENDITURE ITEMS OF THE REGIONAL BUDGET IN RELATION TO OPERATION AND DEVELOPMENT OF THE REGIONAL SOCIO-ECONOMIC SYSTEM

\begin{tabular}{|l|l|l|}
\hline \multirow{2}{*}{$\begin{array}{c}\text { Names of regional budget } \\
\text { expenditure items }\end{array}$} & \multicolumn{2}{|c|}{$\begin{array}{c}\text { The direction of expenditure items in } \\
\text { the structure of the regional socio- } \\
\text { economic system }\end{array}$} \\
\cline { 2 - 3 } operation & \multicolumn{2}{|c|}{ development } \\
\hline National issues & + & + \\
\hline National economy & + & \\
\hline Housing and utilities sector & + & \\
\hline Environmental protection & + & + \\
\hline Education & + & \\
\hline Culture, cinematography & + & + \\
\hline Health care & + & + \\
\hline Social policy & + & + \\
\hline $\begin{array}{l}\text { Physical education and } \\
\text { sport }\end{array}$ & + & \\
\hline Mass media and & + & \\
\hline $\begin{array}{l}\text { Servicing state } \\
\text { municipal debts }\end{array}$ & + & \\
\hline $\begin{array}{l}\text { General intergovernmental } \\
\text { remittances to the budgets } \\
\text { of the budget system of the } \\
\text { Russian Federation }\end{array}$ & + & \\
\hline
\end{tabular}

As for the strategic development of the socio-economic system of the region, the growth rates in the second direction of the budget items of the regional budget, oriented towards development of the socio-economic system of the region, should be higher than in the first, oriented towards the system functioning. The lack of strong connection between budget expenditures and the socio-economic situation in most Russian regions, in our opinion, can be explained by the fact that when approving, developing and putting into practice the strategies for long-term sustainable socioeconomic development of the regions, the budget possibilities of the region are insufficiently analyzed, in particular:
- there is no assessment of the stated strategic goals, objectives, activities with regional budget potential and constraints;

- there are no long-term budget forecasts that allow to assess if the goals, strategies and measures are realistic;

- there is no complete list of documents regulating the budget expenditures of the region in the implementation of strategic directions;

- methodological support linking long-term strategic and budget planning in the region is insufficient.

An empirical study of the budgetary expenditures influence over the indicators of socio-economic development allows us to conclude that the budgetary instruments are extremely low performing and there is practically no budget influence over the socio-economic situation in the regions of Russia. This is due to various factors, and above all, to budget constraints on the formation of revenue sources and spending powers of regional budgets. To solve this problem, the distribution of economic functions between the federal center, the constituent entities of the Russian Federation and municipalities should be revised in terms of independence growth when establishing minimum economic, social and financial standards in the region and forming the budget expenditure and intergovernmental relations with municipalities.

\section{CONCLUSION}

Summing up the above mentioned facts, the work led us to conclude that in order to solve the problems of regional socio-economic development, it is essential to increase the degree of regional budgets influence over socio-economic processes, ensure interconnection between strategic and budget planning of regional development, provide organizational and methodological support of the regional strategic planning process and develop an organizationaleconomic model of regional socio-economic development management with compulsory integration of budget and long-term socio-economic planning at the regional level.

\section{REFERENCES}

[1] R.A. Shichiyah, A.V. Medvedeva, "Theoretical and methodological foundations of the program-targeted management of regional socioeconomic systems", Journal of Kuban State Agrarian University, vol No. 93(09), pp. 1-15, 2013.

[2] A.N. Bobryshev, M.Yu. Kazakov, Improving the monitoring system of the socio-economic development of the region: the micro-and meso-economic aspect. Stavropol: Publishing house LLC Alfa Print, 2011, 203 p.

[3] M.A. Grezina, O.A. Kolchina, I.K. "Shevchenko Typology of regions as an information and analytical toolkit for improving intergovernmental relations in conditions of territorial differentiation", Tomsk State University Bulletin. Economy, vol. 4 (20), p. 122-130, 2012.

[4] L.A. Meshcheryakova, "Evaluation of the potential of the region in increasing tax revenues of the budget', Regional economy: theory and practice, vol. 7, p. 41-44, 2008. 
[5] A.S. Molchan, State support of regional business entities as a factor in the economic regulation of the development of the region's business environment. Scientific works of the Kuban State Technological University. Krasnodar: Kuban State Technical University Publisher, 2015, 126 p.

[6] Yu.S. Avramenko, "Innovations as a result of new opportunities in the development of the socio-economic system of the region", Issues of structuring the economy, vol. 1. pp. 23-25, 2012.

[7] T.K. Gomanova, "Credit market as a factor of regional development", Money and credit, vol. 1, p. 60-63, 2009.

[8] N.I. Sidorova, "Possibilities of using tax instruments for regulating regional development", Problems of Forecasting, vol. 1, p. 96-107, 2003.

[9] A. N.Alekseev, D. L. Savenkov, E. E. Shvakov, N. A. Lebedev, and A. D., Ragulin, "Financial problems of regional development and the ways of their solution in contemporary Russia", Quality - Access to Success, vol. 19(S2), p. 71-75, 2018.

[10] M. V. Zenkina, N. N. Milchakova, L. L. Reshetnikov, andE. N. Shcherbakova, "Some aspects of the regional policy for interbudgetary relations", International Journal of Civil Engineering and Technology, vol. 9(2), p. 765-775, 2018.

[11] Y. V. Ragulina, A. V. Bogoviz, and A. N., Alekseev, "Modeling the management of innovational processes in regional economy", Advances in Intelligent Systems and Computing, vol. 622, p. 568-573, 2018

[12] A. V. Bogoviz, Y. V. Ragulina, A. V. Komarova, A. V. Bolotin, andS. V. Lobova, "Modernization of the approach to usage of region's budget resources in the conditions of information economy development", European Research Studies Journal, vol. 20(3), p. 570577, 2017.

[13] Electronic Publication: Federal Treasury of Russia http://www.roskazna.ru/

[14] Electronic Publication: Federal State Statistics Service http://www.gks.ru/ 